\title{
The tidal volume challenge improves the reliability of dynamic preload indices during robot-assisted laparoscopic surgery in the Trendelenburg position with lung- protective ventilation
}

Joo-Hyun Jun', Rack Kyung Chung ${ }^{2^{*}}$ (B), Hee Jung Baik², Mi Hwa Chung ${ }^{1}$, Joon-Sang Hyeon', Young-Goo Lee ${ }^{3}$ and Sung-Ho Park ${ }^{4}$

\begin{abstract}
Background: The reliability of pulse pressure variation (PPV) and stroke volume variation (SW) is controversial under pneumoperitoneum. In addition, the usefulness of these indices is being called into question with the increasing adoption of lung-protective ventilation using low tidal volume $\left(V_{T}\right)$ in surgical patients. A recent study indicated that changes in PPV or SW obtained by transiently increasing $V_{T}\left(V_{T}\right.$ challenge) accurately predicted fluid responsiveness even in critically ill patients receiving low $V_{T}$. We evaluated whether the changes in PPV and SW induced by a $V_{T}$ challenge predicted fluid responsiveness during pneumoperitoneum.

Methods: We performed an interventional prospective study in patients undergoing robot-assisted laparoscopic surgery in the Trendelenburg position under lung-protective ventilation. PPV, SW, and the stroke volume index (SVI) were measured at a $V_{T}$ of $6 \mathrm{~mL} / \mathrm{kg}$ and 3 min after increasing the $V_{T}$ to $8 \mathrm{~mL} / \mathrm{kg}$. The $V_{T}$ was reduced to $6 \mathrm{~mL} / \mathrm{kg}$, and measurements were performed before and 5 min after volume expansion (infusing 6\% hydroxyethyl starch 6 $\mathrm{ml} / \mathrm{kg}$ over $10 \mathrm{~min}$ ). Fluid responsiveness was defined as $\geq 15 \%$ increase in the SVI.

Results: Twenty-four of the 38 patients enrolled in the study were responders. In the receiver operating characteristic curve analysis, an increase in PPV $>1 \%$ after the $V_{T}$ challenge showed excellent predictive capability for fluid responsiveness, with an area under the curve (AUC) of 0.95 [95\% confidence interval (CI), 0.83-0.99, $P<0.0001$; sensitivity $92 \%$, specificity $86 \%$ ]. An increase in $\mathrm{SW}>2 \%$ after the $\mathrm{V}_{T}$ challenge predicted fluid responsiveness, but showed only fair predictive capability, with an AUC of $0.76(95 \% \mathrm{Cl}, 0.60-0.89, P<0.0006$; sensitivity $46 \%$, specificity $100 \%$ ). The augmented values of PPV and SW following $V_{T}$ challenge also showed the improved predictability of fluid responsiveness compared to PPV and SW values (as measured by $V_{T}$ ) of $6 \mathrm{ml} / \mathrm{kg}$.
\end{abstract}

Conclusions: The change in PPV following the $V_{T}$ challenge has excellent reliability in predicting fluid responsiveness in our surgical population. The change in SW and augmented values of PPV and SW following this test are also reliable.

Trial registration: This trial was registered with Clinicaltrials.gov, NCT03467711, 10th March 2018.

Keywords: Pulse pressure variation, Stroke volume variation, Fluid responsiveness, Tidal volume challenge, Pneumoperitoneum, Trendelenburg position

\footnotetext{
* Correspondence: rkchung@ewha.ac.kr

${ }^{2}$ Department of Anesthesiology and Pain Medicine, Ewha Womans

University, College of Medicine, Anyangcheon-ro, Yangcheon-gu, Seoul 1071,

South Korea

Full list of author information is available at the end of the article
}

(C) The Author(s). 2019 Open Access This article is distributed under the terms of the Creative Commons Attribution 4.0 International License (http://creativecommons.org/licenses/by/4.0/), which permits unrestricted use, distribution, and

reproduction in any medium, provided you give appropriate credit to the original author(s) and the source, provide a link to the Creative Commons license, and indicate if changes were made. The Creative Commons Public Domain Dedication waiver (http://creativecommons.org/publicdomain/zero/1.0/) applies to the data made available in this article, unless otherwise stated. 


\section{Background}

Robot-assisted laparoscopic surgery is increasingly performed due to its many advantages over open surgery, including minimal tissue trauma, fewer surgical complications, and earlier postoperative recovery [1]. However, pneumoperitoneum is essential for adequate exposure in robot-assisted laparoscopic surgery, which has been associated with increased morbidity such as reduced renal blood flow (RBF) and post-operative renal dysfunction [2,3]. As the level of hydration required to maintain RBF under pneumoperitoneum depends on the baseline volume status [4], an adequate assessment of intravascular volume and optimal fluid management are important [5]. However, predicting the fluid responsiveness with clinical signs, such as blood pressure, or urine output or cardiac filling pressure is more difficult during pneumoperitoneum [6, 7].

Dynamic preload indices such as pulse pressure variation (PPV) and stroke volume variation (SVV), are generally accepted as accurate indicators of fluid responsiveness during surgery and in the intensive care unit (ICU) in patients ventilated with tidal volume $\left(\mathrm{V}_{\mathrm{T}}\right)$ of at least $8 \mathrm{ml} / \mathrm{kg}$ or more of predicted body weight (PBW) [8-10]. As dynamic preload indices are generated by cyclic transmission of airway pressure to the pleural and pericardial spaces under positive ventilation, their reliability can be affected by extra-thoracic modification in compliance such as pneumoperitoneum. Several studies have highlighted the effect of intra-abdominal pressure (IAP) on the accuracy and cut-off values of these indices [11-15]. In addition, as the application of lungprotective ventilation using low $\mathrm{V}_{\mathrm{T}}$ with positive end expiratory pressure (PEEP) is gradually increasing in surgical patients [16-18], the usefulness of these indices during robot-assisted laparoscopic surgery has been questioned.

Recently, Myatra et al. developed a functional test called the " $\mathrm{V}_{\mathrm{T}}$ challenge", which includes transiently increasing $\mathrm{V}_{\mathrm{T}}$ from $6 \mathrm{ml} / \mathrm{kg}$ to $8 \mathrm{ml} / \mathrm{kg} \mathrm{PBW}$ and observing the changes in PPV and SVV [19]. They demonstrated that the absolute changes of PPV and SVV values induced by $V_{T}$ challenge, as well as their augmented values, predicted fluid responsiveness with high sensitivity and specificity, even in critically ill patients receiving low $\mathrm{V}_{\mathrm{T}}$ [19]. This test also validated in predicting fluid responsiveness in surgical patients receiving low $\mathrm{V}_{\mathrm{T}}$ [20].

Therefore, the aim of the current study was to investigate the ability of absolute changes in PPV and SVV values induced by $\mathrm{V}_{\mathrm{T}}$ challenge to predict fluid responsiveness in patients undergoing robot-assisted laparoscopic surgery in the Trendelenburg position under lung-protective ventilation. We also assessed the whether augmented values of PPV and SVV following this test are also reliable to predict fluid responsiveness.

\section{Methods}

\section{Study design and patient population}

This interventional prospective study was approved by the institutional review board of Hallym University Kangnam Sacred Heart Hospital (approval number: 2017-09-003). From March to June 2018, adult patients undergoing robot-assisted laparoscopic surgery with pneumoperitoneum in the Trendelenburg position were enrolled after obtaining their written informed consent. The trial was registered prior to patient enrollment at ClinicalTrials.gov (NCT03467711). Exclusion criteria were body mass index $(\mathrm{BMI})>30$ or $<15 \mathrm{~kg} / \mathrm{m}^{2}$, preoperative arrhythmia, moderate to severe valvular heart disease, preoperative left ventricular ejection fraction < $40 \%$, right ventricular dysfunction, intracardiac shunt, 1$\mathrm{s}$ forced expiratory volume $<60 \%$ of predicted value, moderate to severe renal or liver disease, new-onset arrhythmia after anesthesia induction, and contraindications for oesophageal Doppler monitor (ODM) probe insertion (i.e., oesophageal stent, carcinoma of the esophagus or pharynx, previous oesophageal surgery, oesophageal stricture, oesophageal varices, pharyngeal pouch, and severe coagulopathy). During surgery, all patients were placed in the $25^{\circ}$ Trendelenburg position, and pneumoperitoneum was achieved by continuous carbon dioxide insufflation maintaining an IAP of 15 $\mathrm{mmHg}$.

\section{Anesthetic technique}

After the patients arrived at the operating room, pulse oximetry, three-lead electrocardiography (ECG), and non-invasive arterial pressure monitoring were applied. Anesthesia was induced with propofol $(1.5-2.5 \mathrm{mg} / \mathrm{kg})$ and remifentanil $(0.05-0.15 \mu \mathrm{g} / \mathrm{kg} /$ min), and tracheal intubation was facilitated with rocuronium $(0.8 \mathrm{mg} / \mathrm{kg})$. The patient's lungs were mechanically ventilated with a mixture of oxygen in air, with an inspired oxygen fraction of 0.5 using the volume-controlled mode. $\mathrm{V}_{\mathrm{T}}$ was adjusted to $6 \mathrm{ml} / \mathrm{kg}$ PBW (determined as $\mathrm{x}+0.91$ [height (in $\mathrm{cm}$ ) -152.4 ], where $\mathrm{x}=50$ for males and $\mathrm{x}=45.5$ for females) [21]. The PEEP of $5 \mathrm{~cm} \mathrm{H} \mathrm{H}_{2} \mathrm{O}$ was applied without inspiratory pause. Respiratory rate (RR) was adjusted to maintain an end-tidal carbon dioxide tension between 35 and $40 \mathrm{mmHg}$. The inspiratory to expiratory ratio was set to $1: 2$. Peak inspiratory airway pressure (PIP) and compliance of the respiratory system (Crs) were recorded from the anesthesia machine (Datex-Ohmeda Avance $\mathrm{CS}^{2}$ Anesthesia Machine; GE Healthcare, Helsinki, Finland). Anesthesia was maintained with continuous infusion of remifentanil $(0.02-0.2 \mu \mathrm{g} / \mathrm{kg} / \mathrm{min})$ and sevoflurane $(1.5-2.5$ vol\%) to maintain a bispectral index between 40 and 60. 


\section{Hemodynamic monitoring}

After induction of anesthesia, a radial arterial catheter and ODM probe (CardioQ; Deltex Medical, Chichester, UK) were inserted. Both were connected to the CardioQ-ODM+ (Deltex Medical Ltd.) monitor.

The ODM probe was positioned to obtain the optimum signal for descending aorta blood velocity. Stroke volume index (SVI), and peak velocity (PV) were measured continuously and displayed, and their mean values were calculated over $10 \mathrm{~s}$.

After zeroing the arterial transducer, a flush test was performed to ensure that the arterial pressure measurement system was critically damped. The arterial pulse pressure wave was simultaneously monitored through the patient monitor (CARESCAPE Monitor B850; GE Healthcare) and CardioQ-ODM+ monitor using a serial cable. The patient monitor displayed the automatically calculated PPV in real time using the algorithms described previously [22].

$$
\mathrm{PPV}(\%)=\left[\left(\mathrm{PP}_{\max }-\mathrm{PP}_{\min }\right) / \mathrm{PP}_{\text {mean }}\right] \times 100
$$

where $\mathrm{PP}_{\max }$ and $\mathrm{PP}_{\text {min }}$ represent the maximum and minimum arterial pulse pressure $(\mathrm{PP})$, and $\mathrm{PP}_{\text {mean }}$ is the mean arterial PP.

The CardioQ-ODM+ monitor combines ODM with pulse pressure wave analysis to measure SVI. It uses ODM-derived SVI for initial and periodic calibrations, and then continuously calculates pulse pressure wave analysis-derived SVI using the Liljestrand-Zander formula [23]. By continuous beat detection and analysis, the SV, SVI, and SVV were displayed continuously in a separate pressure-based data window as a column of values. SVV were obtained as described previously, regardless of the respiratory cycle [24].

$$
\operatorname{SVV}(\%)=\left[\left(\mathrm{SV}_{\max }-\mathrm{SV}_{\text {min }}\right) / \mathrm{SV}_{\text {mean }}\right] \times 100
$$

where $\mathrm{SV}_{\text {min }}$ and $\mathrm{SV}_{\max }$ are the minimum and maximum SV values over one respiratory cycle, respectively.

All values were averages of at least three consecutive measurements acquired over $30 \mathrm{~s}$. An independent investigator who was trained in maneuvering the ODM probe but was not involved in the present study assessed ODM and all other variables during the study. ODM is routinely used to monitor surgical patients in our center and shows good inter-observer reliability [14].

\section{Study protocol}

Figure 1 shows a schematic representation of the protocol, which was initiated at least $1 \mathrm{~h}$ after increasing IAP to $15 \mathrm{mmHg}$, and after stabilization of hemodynamic parameters, defined as changes in mean arterial pressure (MAP) $<10 \%$ during $5 \mathrm{~min}$. In addition, to minimize acute changes in IAP and sympathetic tone due to ongoing surgery $[25,26]$, which could confound the effects of fluid challenge, the study protocol was performed with little or no surgical stimulation (absence of cautery and instrumentation of intra-abdominal structures).

We first measured the hemodynamic response to $V_{T}$ challenge, and then performed volume expansion (VE) to assess the subsequent changes in SVI. The first set of measurements, including (HR), MAP, SVI, PV, PIP, $C_{\mathrm{rs}}$, PPV with $6 \mathrm{ml} / \mathrm{kg} \mathrm{PBW} \mathrm{V}_{\mathrm{T}}$ ventilation $\left(\mathrm{PPV}_{6}\right)$, and SVV with $6 \mathrm{ml} / \mathrm{kg} P B W V_{T}$ ventilation $\left(\mathrm{SVV}_{6}\right)$, were recorded at baseline (T1, base 1). After the baseline measurement, $\mathrm{V}_{\mathrm{T}}$ was increased from 6 to $8 \mathrm{ml} / \mathrm{kg} \mathrm{PBW}$ for $3 \mathrm{~min}$ without changing the RR. During the last minute of high $\mathrm{V}_{\mathrm{T}}$ ventilation, measurements of the above-mentioned hemodynamic and respiratory variables, including PPV with $8 \mathrm{ml} / \mathrm{kg} \mathrm{PBW} \mathrm{V}_{\mathrm{T}}$ ventilation $\left(\mathrm{PPV}_{8}\right)$ and $\mathrm{SVV}$ with $8 \mathrm{ml} / \mathrm{kg} \mathrm{PBW} \mathrm{V}_{\mathrm{T}}$ ventilation $\left(\mathrm{SVV}_{8}\right)$, were again recorded (T2). The changes in PPV and SVV values

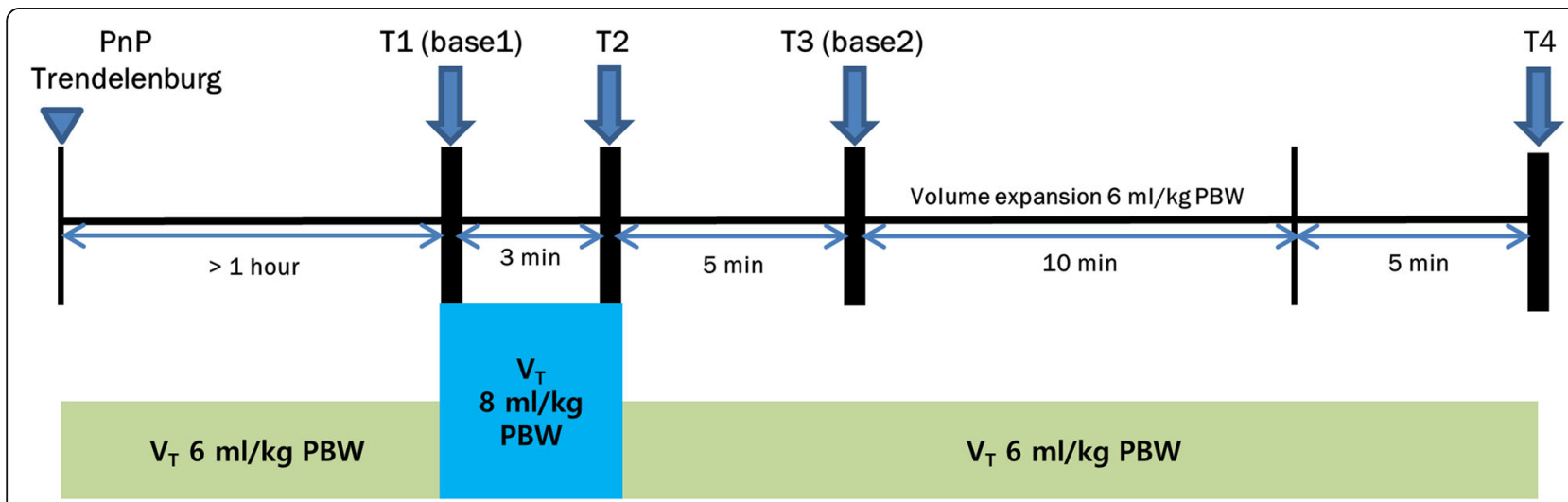

Fig. 1 Study protocol. Arrows indicate time points at which measurements were made. PnP, pneumoperitoneum; $V_{T}$, tidal volume; PBW, predicted body weight 
induced by $\mathrm{V}_{\mathrm{T}}$ challenge $\left(\Delta \mathrm{PPV}_{6-8}\right.$ and $\left.\Delta \mathrm{SVV}_{6-8}\right)$ were calculated as follows:

$$
\begin{aligned}
& \Delta \mathrm{PPV}_{6-8}=\mathrm{PPV}_{8}-\mathrm{PPV}_{6} \\
& \Delta \mathrm{SVV}_{6-8}=\mathrm{SVV}_{8}-\mathrm{SVV}_{6} .
\end{aligned}
$$

The percentage change in PPV and SVV values induced by $\mathrm{V}_{\mathrm{T}}$ challenge $\left(\% \Delta \mathrm{PPV}_{6-8}\right.$ and $\left.\% \Delta \mathrm{SVV}_{6-8}\right)$ also calculated.

After the $\mathrm{V}_{\mathrm{T}}$ was returned to $6 \mathrm{ml} / \mathrm{kg} \mathrm{PBW}$ and all of the hemodynamic variables had returned to baseline values (variations $<10 \%$ ), VE was performed for $10 \mathrm{~min}$ using an infusion of 6\% hydroxyethyl starch (HES 130/ 0.4, Volulyte; Fresenius Kabi, Stans, Switzerland) $6 \mathrm{ml} / \mathrm{kg}$ PBW. Two sets of measurements (HR, MAP, SVI, PV, PIP, Crs, PPV, and SVV) were performed before (T3, base 2) and 5 min after VE (T4) [27, 28]. Percentage differences in ODM-derived SVIs before and after VE were used as principal indicators of fluid responsiveness. Patients were classified as responders to VE if they showed an increase in $\mathrm{SVI} \geq 15 \%$ and as non-responders if they showed an increase $<15 \%[29,30]$. The changes in SVV and PPV values after VE $\left(\triangle P P V_{V E}\right.$ and $\left.\triangle S V V_{V E}\right)$ were calculated as follows:

$$
\begin{aligned}
& \Delta \mathrm{PPV}_{\mathrm{VE}}=\mathrm{PPV}(\mathrm{T} 4)-\mathrm{PPV}(\text { base 2, T3) } \\
& \Delta \mathrm{SVV}_{\mathrm{VE}}=\mathrm{SVV}(\mathrm{T} 4)-\mathrm{SVV}(\text { base 2, T3). }
\end{aligned}
$$

\section{Statistical analysis}

MedCalc for Windows (ver. 15.6.1; MedCalc Software, Ostend, Belgium) was used to calculate sample size. The sample size was determined using the difference between the area under the curve (AUC) of 0.75 (alternative hypothesis that $\mathrm{PPV}_{8}$ can predict fluid responsiveness after VE) and 0.5 (null hypothesis). At least 38 patients were required to detect an AUC difference of 0.25 with a type I error of 0.05 and a desired power of 0.80 , assuming equal numbers of responders and non-responders. With the expectation of a $10 \%$ dropout rate, 42 patients were enrolled in the study.

The normality of the continuous data was tested with the Shapiro-Wilk test. Data are presented as the mean (SD), median [interquartile range (IQR)], or number of patients (\%).Student's $t$-test or the MannWhitney $U$ test for continuous variables, and the chisquare test for categorical data, were used to compare patient characteristics between responders and nonresponders. The hemodynamic parameters were compared between responders and non-responders using the Mann-Whitney U-test or $t$-test, as appropriate. The effects of the temporary increase in $V_{T}$ from 6 to $8 \mathrm{ml} / \mathrm{kg}$ and VE on hemodynamic parameters were assessed using the paired $t$-test or the Wilcoxon signed-rank sum test after the normality test. A
Bonferroni-adjusted $P$-value (normal $P$-value multiplied by the number of outcomes being tested) was used to control for multiple comparisons.

The relations between percentage changes in SVI after $\mathrm{VE}$ and hemodynamic parameters before VE $\left(\mathrm{PPV}_{6}\right.$, $\mathrm{PPV}_{8}, \quad \Delta \mathrm{PPV}_{6-8}, \quad \mathrm{SVV}_{6}, \quad \mathrm{SVV}_{8}$, and $\left.\Delta \mathrm{SVV}_{6-8}\right)$ were assessed using Spearman's rank correlation. The relationship between the percentage changes in SVI after and the changes in PPV and SVV after VE $\left(\triangle P P V_{V E}\right.$ and $\Delta S V V_{V E}$ ) were also assessed using Spearman's rank correlation analysis. The intraclass correlation between the SVI, PPV, and SVV measurements at the two baseline steps (T1 and T3) was measured using random-effects models [31].

To test the abilities of dynamic preload indices to predict fluid responsiveness, the AUCs of receiver operating characteristic (ROC) curves were calculated and compared using the DeLong method. Briefly, the general interpretations of a test according to the value of the AUC of the ROC were as follows: $\mathrm{AUC}=0.5$, no better than chance, a useless test with no prediction possible; $\mathrm{AUC}=0.6-0.69$, a test with a poor predictive capability; $\mathrm{AUC}=0.7-0.79$, a fair test; AUC $=0.8-0.89$, a test with good predictive capability; $\mathrm{AUC}=0.9-0.99$, an excellent test; $\mathrm{AUC}=1.0$, a perfect test with the best possible prediction. An optimal threshold value was determined for each variable to maximize the Youden index (sensitivity + specificity - 1). Considering the possibility of an overlap between responders and non-responders, we determined a grey zone for dynamic preload indices, considering a low cut-off value including $90 \%$ of negative fluid challenge responses, and a high cut-off value predicting positive fluid challenge in $90 \%$ of cases [32].

Statistical analyses were performed using MedCalc (ver. 15.6.1) and SPSS software (ver. 24.0; IBM Corp., Armonk, NY, USA) and R package (version 3.4.2; https://www.r-project.org/). In all analyses, $P<0.05$ was taken to indicate statistical significance.

\section{Results}

\section{Patient characteristics}

Of the 49 patients included in the initial screen, 42 fulfilled the inclusion criteria and were enrolled in the study. Four patients were excluded; one developed intraoperative subcutaneous emphysema and required a ventilator mode change, one had severe hypotension during $\mathrm{VE}$ and required vasopressor support, one developed paroxysmal atrial fibrillation during surgery, and the remaining patient's arterial pressure measurement system was critically damped. Among the 38 patients included in the final analysis, 24 patients $(63 \%)$ were responders and 14 (37\%) were non-responders (Fig. 2). 


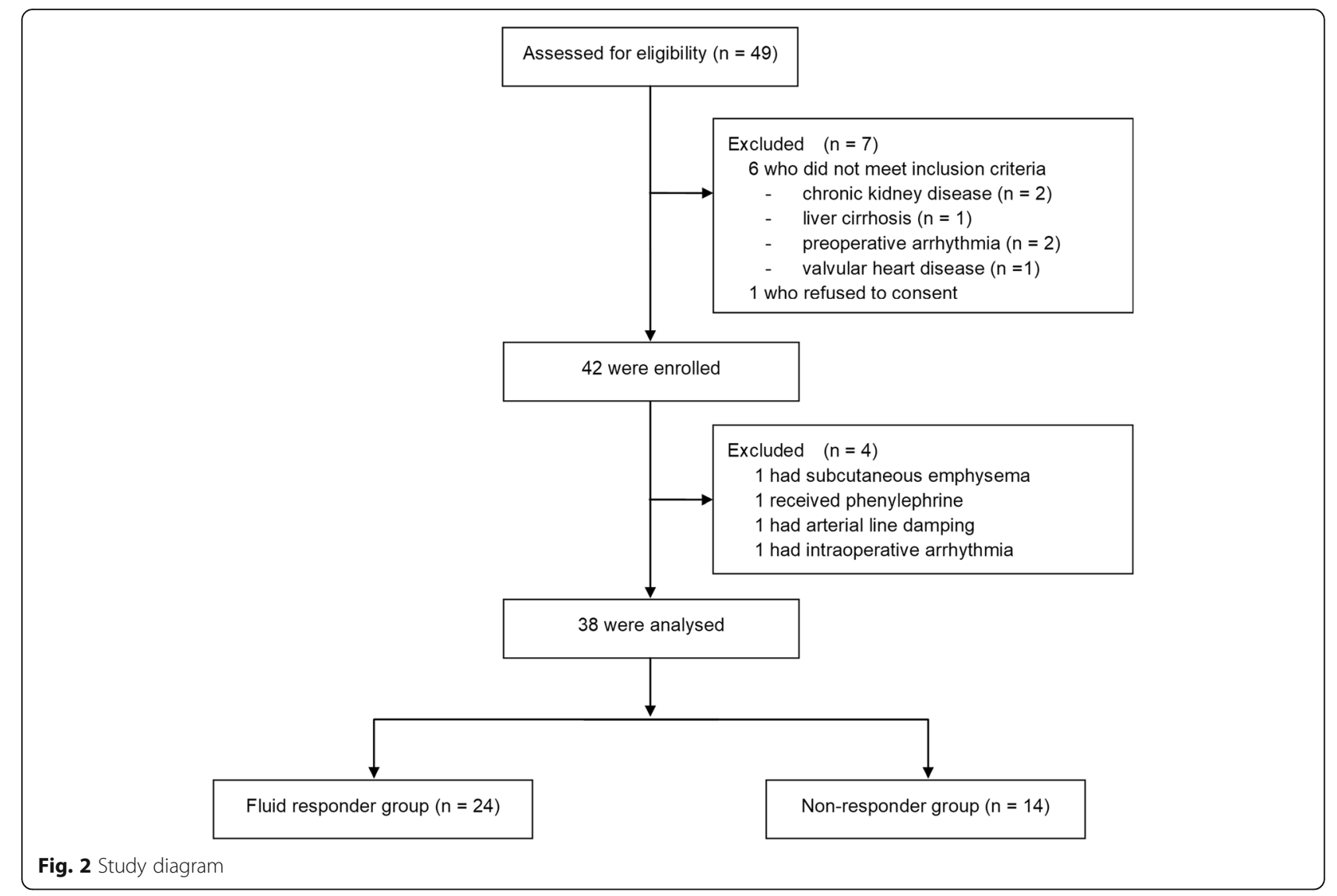

There were no significant differences in age, PBW, or BMI between responders and non-responders, whereas the surgery type and sex distribution differed between the two groups (Table 1). The intraclass correlation between the SVI, PPV, and SVV measurements at the two baseline steps (T1 and T3) were 0.98 [95\% confidence interval (CI), 0.96-0.99], 0.96 (95\% CI, 0.92-0.98), and 0.81 (95\% CI, 0.64-0.90), respectively.

\section{Effects of $V_{T}$ challenge and VE on hemodynamic and respiratory variables}

At baseline, with $6 \mathrm{ml} / \mathrm{kg} \mathrm{PBW} \mathrm{V}_{\mathrm{T}}$ ventilation, no significant differences were found in any hemodynamic variables, including $\mathrm{PPV}_{6}$ and $\mathrm{SVV}_{6}$, between responders and non-responders. After increasing $V_{T}$ to $8 \mathrm{ml} / \mathrm{kg}$ PBW, MAP decreased and PPV and SVV increased significantly only in responders, resulting in significant differences in MAP, PPV $\left(\mathrm{PPV}_{8}\right)$, and SVV $\left(\mathrm{SVV}_{8}\right)$ between responders and non-responders. Baseline PIP and Crs were comparable between the two groups and increased significantly after $\mathrm{V}_{\mathrm{T}}$ challenge in responders and nonresponders (Table 2).

Significant changes in PIP, Crs, SVI, and PPV were induced in responders and non-responders after VE, while significant decreases in HR and SVV were induced only in responders (Table 2).

\section{Relationships between changes in PPV and SVV induced} by VE and percentage changes in SVI induced by VE $\mathrm{PPV}_{\mathrm{VE}}$ and $\triangle S V V_{\mathrm{VE}}$ were significantly correlated with VE-induced percentage changes in SVI $(\mathrm{r}=-0.61[95 \%$ $\mathrm{CI}-0.78$ to -0.36$], P<0.001 ; \mathrm{r}=-0.44$ [95\% CI -0.67 to -0.14 ], $P=0.006$, respectively) (Fig. 3), indicating the ability of these variables to track changes in SVI induced by VE during pneumoperitoneum.

\section{Prediction of fluid responsiveness}

In the ROC curve analysis, $\triangle \mathrm{PPV}_{6-8}$ showed excellent predictive capability for fluid responsiveness with an AUC of 0.95 (95\% CI $0.83-0.99, P<0.0001) . \Delta \mathrm{PPV}_{6-8}>$ $1 \%$ identified responders with sensitivity of $92 \%$ (95\% CI $73-99)$ and specificity of $86 \%$ (95\% CI $57-98) . \Delta \mathrm{SVV}_{6-8}$ could also predict fluid responsiveness but showed only fair predictive capability, with an AUC of 0.76 (0.60$0.89)$. The $\Delta \mathrm{SVV}_{6-8}>2 \%$ identified responders with a sensitivity $46 \%(95 \%$ CI $26-67)$ and specificity of $100 \%$ (95\% CI 77-100) (Table 3).

$\mathrm{PPV}_{6}$ showed poor ability to predict fluid responsiveness, with an AUC of 0.69 (95\% CI 0.52-0.83, $P=0.036$ ), 
Table 1 Patient Characteristics

\begin{tabular}{|c|c|c|c|c|}
\hline & $\begin{array}{l}\text { Overall } \\
(N=38)\end{array}$ & $\begin{array}{l}\text { Responders } \\
(n=24)\end{array}$ & $\begin{array}{l}\text { Non-responders } \\
(n=14)\end{array}$ & $P$-value \\
\hline Age, years (range) & $49.5(45-62.3)$ & $56.5(45.3-62.8)$ & $47(41-52.5)$ & 0.058 \\
\hline Sex (male/female) & $17 / 21$ & $14 / 10$ & $3 / 11$ & 0.043 \\
\hline Height, cm & $162 \pm 7.0$ & $163.5 \pm 7.2$ & $161.5 \pm 6.9$ & 0.406 \\
\hline Predicted body weight, kg & $57 \pm 7.8$ & $58.26 \pm 8.0$ & $54.8 \pm 7.2$ & 0.717 \\
\hline Body mass index, $\mathrm{kg} / \mathrm{m}^{2}$ & $24.4 \pm 2.5$ & $24.5 \pm 2.2$ & $24.2 \pm 2.9$ & 0.664 \\
\hline Hypertension & $9(29)$ & $6(28.6)$ & $3(30)$ & 1.000 \\
\hline Surgery type, n (\%) & & & & 0.102 \\
\hline Radical prostatectomy & $18(47.4)$ & $15(62.5)$ & $3(21.4)$ & \\
\hline Hysterectomy & $14(36.8)$ & $6(25)$ & $8(57.1)$ & \\
\hline Myomectomy & $6(15.8)$ & $3(12.5)$ & $3(21.4)$ & \\
\hline
\end{tabular}

Values are mean $\pm S D$, median (IQR) or number (\%)

Table 2 Hemodynamic and Respiratory Variables at Baseline, after the Tidal Volume Challenge, before Volume Expansion, and after Volume Expansion in Responders $(n=24)$ and Non-responders $(n=14)$

\begin{tabular}{|c|c|c|c|c|c|c|}
\hline & $\begin{array}{l}\mathrm{T} 1 \\
\text { Base } 1 \\
\left(\mathrm{~V}_{\mathrm{T}} 6 \mathrm{ml} / \mathrm{kg}\right) \\
\end{array}$ & $\begin{array}{l}\mathrm{T} 2 \\
\text { Increased } \mathrm{V}_{\mathrm{T}} \\
\left(\mathrm{V}_{\mathrm{T}} 8 \mathrm{ml} / \mathrm{kg}\right)\end{array}$ & P1 Value & $\begin{array}{l}\text { T3 } \\
\text { Base } 2 \\
\left(V_{T} 6 \mathrm{ml} / \mathrm{kg}\right) \\
\end{array}$ & $\begin{array}{l}\text { T4 } \\
\text { After VE } \\
\left(V_{T} 6 \mathrm{ml} / \mathrm{kg}\right) \\
\end{array}$ & P2 Value \\
\hline \multicolumn{7}{|l|}{ HR (beats/min) } \\
\hline Responders & 74 (68-86) & $74(68-85)$ & 0.492 & 75 (69-85) & $73(66-82)$ & 0.012 \\
\hline Non-responders & $68(65-77)$ & $68(65-77)$ & $>0.99$ & $68(63-75)$ & $68(64-77)$ & $>0.99$ \\
\hline \multicolumn{7}{|l|}{ MAP $(\mathrm{mm} \mathrm{Hg})$} \\
\hline Responders & $82 \pm 10$ & $79 \pm 12$ & 0.036 & $80 \pm 13$ & $85 \pm 11$ & 0.078 \\
\hline Non-responders & $91 \pm 13$ & $89 \pm 11$ & $>0.99$ & $87 \pm 11$ & $87 \pm 10$ & $>0.99$ \\
\hline \multicolumn{7}{|l|}{$\mathrm{PIP}\left(\mathrm{cm} \mathrm{H}_{2} \mathrm{O}\right)$} \\
\hline Responders & $26 \pm 3$ & $31 \pm 4$ & $<0.001$ & $26 \pm 3$ & $27 \pm 3$ & $<0.001$ \\
\hline Non-responders & $25 \pm 3$ & $30 \pm 4$ & 0.006 & $25 \pm 3$ & $26 \pm 3$ & 0.016 \\
\hline \multicolumn{7}{|l|}{$\operatorname{Crs}\left(\mathrm{ml} / \mathrm{cmH}_{2} \mathrm{O}\right)$} \\
\hline Responders & $17(14.3-19)$ & $17(15-19)$ & 0.018 & $16(14-19)$ & 15.5 (14-18) & $<0.001$ \\
\hline Non-responders & $16.5(13.8-18.3)$ & $17(14.8-18.3)$ & 0.066 & $16(13.8-17.3)$ & $15(13-17)$ & 0.024 \\
\hline \multicolumn{7}{|l|}{$\mathrm{SVI}\left(\mathrm{ml} / \mathrm{min}^{2}\right)$} \\
\hline Responders & $41.5 \pm 8.2$ & $40.6 \pm 8.9$ & $>0.99$ & $40.2 \pm 9.0$ & $50.6 \pm 10.9$ & $<0.001$ \\
\hline Non-responders & $50.5 \pm 15.2$ & $52.2 \pm 15.3$ & 0.864 & $52 \pm 15.7$ & $55.2 \pm 16.8$ & 0.018 \\
\hline \multicolumn{7}{|l|}{ PPV (\%) } \\
\hline Responders & $7(5.3-8.8)$ & $9(8-13)^{*}$ & $<0.001$ & $7.5(5.3-9.8)^{*}$ & $3.5(3-5)$ & $<0.001$ \\
\hline Non-responders & $5.5(3.8-6.5)$ & $6(3.8-7.3)$ & 0.132 & $5(3.8-6)$ & $3(1.8-3.8)$ & 0.006 \\
\hline \multicolumn{7}{|l|}{ SW (\%) } \\
\hline Responders & $5(4-6)$ & $6.5(4-9)^{*}$ & $<0.001$ & $6(4-7)^{*}$ & $4(3-5)$ & 0.042 \\
\hline Non-responders & $5(2.8-5)$ & $4(3-5.3)$ & $>0.99$ & $4(2.8-5)$ & $4(2.8-5)$ & $>0.99$ \\
\hline
\end{tabular}

HR Heart rate, RR Respiratory rate, MAP Mean arterial pressure, PIP Peak inspiratory pressure, Crs Respiratory compliance, SVI Stroke volume index, PPV Pulse pressure variation, SVV Stroke volume variation, VT Challenge tidal volume challenge, VE Volume expansion

Data are mean \pm SD or median (IQR). Patients were considered responders if the stroke volume index increased by at least $15 \%$ after volume expansion (6\% hydroxyethyl starch $6 \mathrm{ml} / \mathrm{kg}$ for $10 \mathrm{~min}$ )

${ }^{*} P<0.05$ comparison between responders and non-responders $(n=14)$ at each time point; $P 1$-values are for intragroup comparisons of values before $(\mathrm{T} 1)$ and after the tidal volume challenge (T2); $P 2$-values are for intragroup comparisons of values before (T3) and after volume expansion (T4); $P$-values were adjusted using the Bonferroni correction 

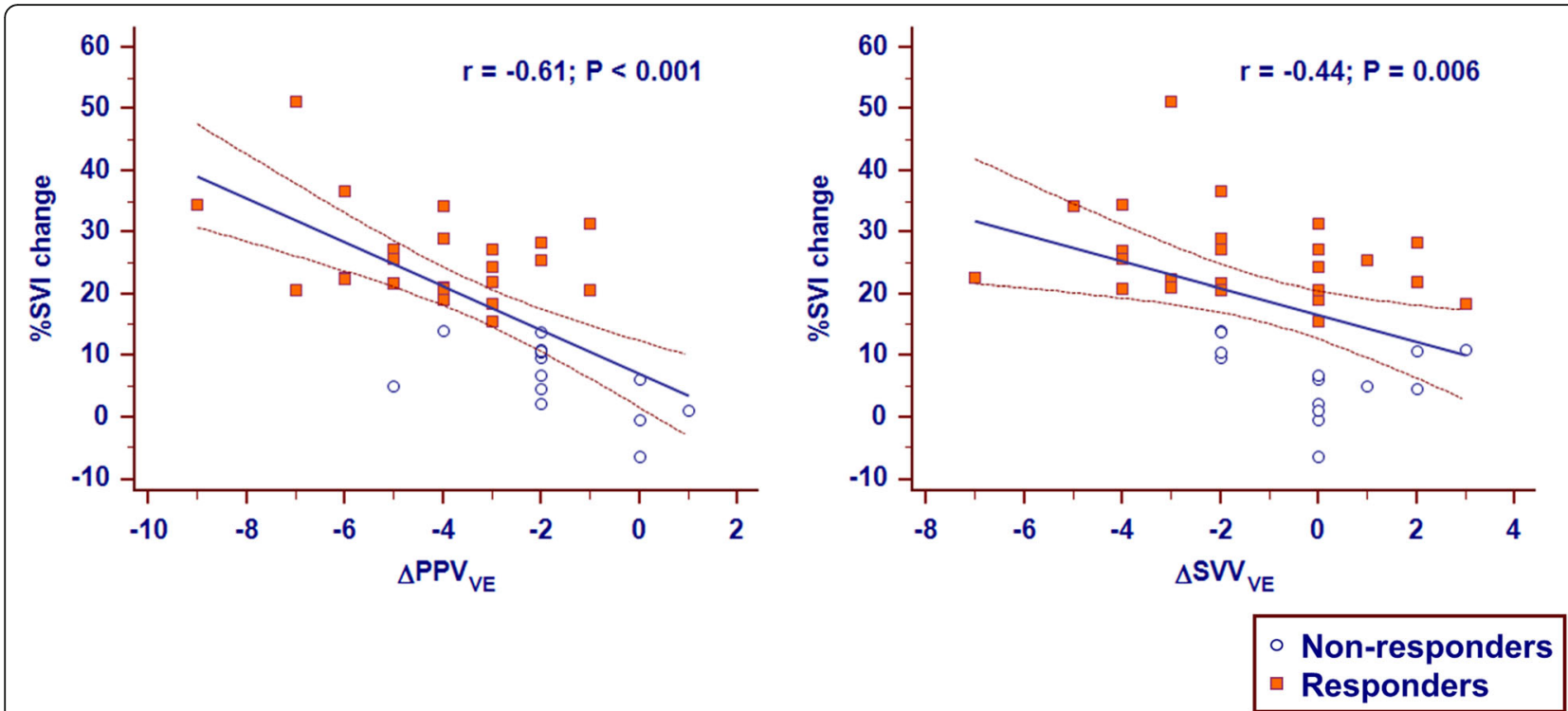

Fig. 3 Relationship between volume expansion-induced changes in pulse pressure variation and stroke volume variation and volume expansioninduced percentage changes in the stroke volume index (SVI). $\triangle P P V_{V E}$, changes in pulse pressure variation after volume expansion; $\Delta S W_{V E}$ changes in stroke volume variation after volume expansion

but $\mathrm{PPV}_{8}$ showed good ability, with an AUC of 0.85 (95\% CI $0.70-0.95, P<0.0001)$. $\mathrm{SVV}_{6}$ was not predictive of fluid responsiveness, but $\mathrm{SVV}_{8}$ showed fair predictive ability, with an AUC of 0.77 (95\% CI 0.61-0.89). The optimal threshold values of $\mathrm{PPV}_{8}$ and $\mathrm{SVV}_{8}$ were $7 \%$ [sensitivity 79\% (95\% CI 58-93); specificity 79\% (95\% CI $49-$ 95)] and 5\% [sensitivity 67\% (95\% CI 45-84); specificity 79\% (95\% CI 49-95)], respectively (Table 3). The AUCs for $\triangle \mathrm{PPV}_{6-8}$ and $\mathrm{PPV}_{8}$ were significantly greater than those for $\mathrm{PPV}_{6}(P<0.001$ and $P=0.003$, respectively $)$. The AUCs for $\mathrm{SVV}_{8}$ were significantly greater than those for $\operatorname{SVV}_{6}(P=0.007)$ but there were no significant differences in the AUCs for $\triangle \mathrm{SVV}_{6-8}$ and $\operatorname{SVV}_{6}(P=0.11)$. No significant differences were found between the AUCs for $\triangle \mathrm{PPV}_{6-8}$ and $\mathrm{PPV}_{8}(P=0.09)$ or between those for $\mathrm{SVV}_{6-8}$ and $\mathrm{SVV}_{8}(P=0.85)$ (Fig. 4).

\section{Discussion}

In this study on patients undergoing robot-assisted laparoscopic surgery in the Trendelenburg position under lung-protective ventilation, we demonstrated that absolute change in PPV values obtained by $\mathrm{V}_{\mathrm{T}}$ challenge $\left(\triangle \mathrm{PPV}_{6-8}\right)$ can predict fluid responsiveness with excellent predictive capability, whereas $\Delta \mathrm{SVV}_{6-8}$ showed only fair predictive capability. The optimal thresholds of $\triangle \mathrm{PPV}_{6-8}$ and $\triangle \mathrm{SVV}_{6-8}$ were $>1 \%$ and $>2 \%$, respectively. This study also showed that the augmentation of PPV and SVV following $\mathrm{V}_{\mathrm{T}}$ challenge improved the predictability of fluid responsiveness compared to PPV and SVV measured with a $V_{T}$ of $6 \mathrm{ml} / \mathrm{kg}$.
Our study demonstrated that a $\mathrm{V}_{\mathrm{T}}$ challenge improved the predictive power of PPV and SVV values, even in patients with elevated IAP. Because PPV and SVV values are augmented in fluid responders, but not in non-responders, the absolute changes in the PPV and SVV values induced by increased $\mathrm{V}_{\mathrm{T}}$ could also be used to predict fluid responsiveness, which is consistent with studies of Myatra et al. [19] and Messina et al. [20].

However, the cut-off values of $\triangle \mathrm{PPV}_{6-8}$ and $\Delta \mathrm{SVV}_{6-8}$ in our study and in the study of Messina et al. [20] were lower than those reported by Myatra et al. [19]. There are several possible explanations for this discrepancy. The extent of airway pressure transmission to the pleural space is inversely proportional to chest wall compliace $\left(\mathrm{C}_{\mathrm{cw}}\right)$ and proportional to lung compliance $\left(\mathrm{C}_{\mathrm{L}}\right)$ $[33,34]$. Messina et al. described that their cut-off values was lower because Myatra et al. enrolled critically ill patients in the ICU with reduced $\mathrm{C}_{\mathrm{cw}}$ reported at $30 \%$, while they enrolled healthy surgical patients $[20,35]$. As pneumoperitoneum has been known to decreases $\mathrm{C}_{\mathrm{cw}}$ [36], higher cut-off values could be expected in our study population. However, adding a steep Trendelenburg position to pneumoperitoneum reduces $\mathrm{Ccw}$ as well as $C_{L}$ [37], which may have caused the cut off value lower than expected. In addition to the aforementioned factors, different hemodynamic characteristics of the patients may contribute to different cut-off values; Myatra et al. studied critically ill patients with acute circulatory failure, whereas our study population consisted of patients with no clinical signs of shock. That most our study population were in the 'grey zone' where 
Table 3 Prediction of Fluid Responsiveness based on the ROC Curves of Various Indices

\begin{tabular}{|c|c|c|c|c|c|c|c|}
\hline & $\mathrm{AUC}(95 \% \mathrm{Cl})$ & $P$-value & $\begin{array}{l}\text { Cut-off value, } \\
\%\end{array}$ & $\begin{array}{l}\text { Sensitivity (95\% } \\
\text { Cl) }\end{array}$ & $\begin{array}{l}\text { Specificity (95\% } \\
\text { Cl) }\end{array}$ & Grey zone (\%) & Patients in the grey zone number (\%) \\
\hline $\mathrm{PPV}_{6}$ & $\begin{array}{l}0.69(0.52- \\
0.83)\end{array}$ & 0.036 & $>6$ & $54(33-74)$ & 79 (49-95) & 3.2 to 7.8 & $22(58)$ \\
\hline $\mathrm{SW}_{6}$ & $\begin{array}{l}0.56(0.39- \\
0.72)\end{array}$ & 0.563 & - & - & - & & \\
\hline $\mathrm{PPV}_{8}$ & $\begin{array}{l}0.85(0.70- \\
0.95)\end{array}$ & $\begin{array}{l}< \\
0.0001\end{array}$ & $>7$ & $79(58-93)$ & 79 (49-95) & 6.2 to 8.6 & $10(26)$ \\
\hline $\mathrm{SW}_{8}$ & $\begin{array}{l}0.77(0.61- \\
0.89)\end{array}$ & 0.0003 & $>5$ & $67(45-84)$ & $79(49-95)$ & 2.7 to 6.3 & $21(55)$ \\
\hline$\Delta \mathrm{PPV}_{6-8}$ & $\begin{array}{l}0.95(0.83- \\
0.99)\end{array}$ & $\begin{array}{l}< \\
0.0001\end{array}$ & $>1$ & $92(73-99)$ & $86(57-98)$ & 1 to 1.3 & $9(24)$ \\
\hline$\Delta S W_{6-8}$ & $\begin{array}{l}0.76(0.60- \\
0.89)\end{array}$ & 0.0006 & $>2$ & $46(26-67)$ & $100(77-100)$ & -1.5 to 1.4 & $21(55)$ \\
\hline$\% \Delta P P V_{6-8}$ & $\begin{array}{l}0.87(0.72- \\
0.96)\end{array}$ & $\begin{array}{l}< \\
0.0001\end{array}$ & $>25$ & $83(63-95)$ & $79(49-95)$ & 20.5 to 46 & $12(32)$ \\
\hline$\% \Delta S W_{6-8}$ & $\begin{array}{l}0.71(0.55- \\
0.85)\end{array}$ & 0.02 & $>16.7$ & $67(45-85)$ & 79 (49-95) & -32 to 95 & $27(71)$ \\
\hline
\end{tabular}

$R O C$ Receiver operating characteristic, AUC Area under the curve, $\mathrm{Cl}$ Confidence interval, $P P V_{6}$ Pulse pressure variation during tidal volume at $6 \mathrm{ml} / \mathrm{kg}$ predicted body weight (PBW), $S_{6} V_{6}$ Stroke volume variation during tidal volume at $6 \mathrm{ml} / \mathrm{kg} \mathrm{PBW}, P P V_{8}$ Pulse pressure variation during tidal volume at $8 \mathrm{ml} / \mathrm{kg}$ PBW, $S V V_{8}$ Stroke volume variation during tidal volume at $8 \mathrm{ml} / \mathrm{kg} \mathrm{PBW,} \triangle P P V_{6-8}$ Change in value of pulse pressure variation after tidal volume challenge, $\triangle S V_{6-8} C$ hange in value of stroke volume variation after tidal volume challenge, $\% \triangle P P V_{6-8}$ Percentage change in value of pulse pressure variation after tidal volume challenge, $\% \Delta S V V_{6-8}$ Percentage change in value of stroke volume variation after tidal volume challenge

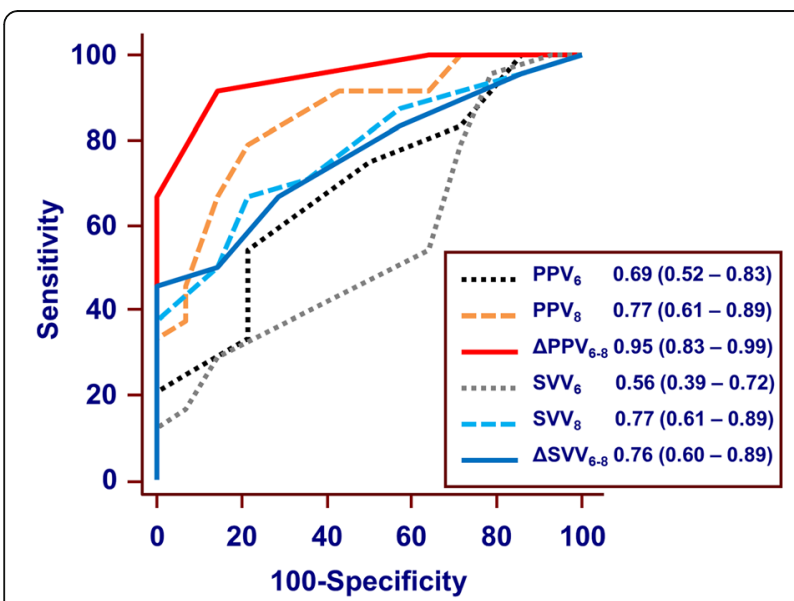

Fig. 4 Comparison of receive -operating characteristic curves of $\mathrm{PPV}_{6}, \mathrm{PPV}_{8}, \Delta \mathrm{PPV}_{6-8}, \mathrm{SW}_{6}, \mathrm{SW}_{8}$ and $\Delta \mathrm{SW}_{6-8}$ to predict fluid responsiveness during robot-assisted laparoscopic surgery in the Trendelenburg position under lung-protective ventilation. PPV 6 , pulse pressure variation during tidal volume at $6 \mathrm{ml} / \mathrm{kg}$ predicted body weight (PBW); PPV $_{8}$, pulse pressure variation during tidal volume at $8 \mathrm{ml} / \mathrm{kg}$ PBW; $\triangle \mathrm{PPV}_{6-8}$, change in value of pulse pressure variation after tidal volume challenge; $\mathrm{SW}_{6}$, stroke volume variation during tidal volume at $6 \mathrm{ml} / \mathrm{kg}$ predicted body weight (PBW); $\mathrm{SW}_{8,}$ stroke volume variation during tidal volume at $8 \mathrm{ml} / \mathrm{kg} \mathrm{PBW;} \triangle \mathrm{SW}_{6-}$ ${ }_{8}$, change in value of stroke volume variation after tidal volume challenge; area under the ROC curve appears in cartouche with 95\% confidence interval responders and non-responders are not well separated [32], would also have contributed to the less profound changes in PPV and SVV values.

Unlike Myatra et al. [19] and Messina et al. [20]., the absolute change in SVV after $V_{T}$ challenge showed only fair ability to predict true fluid responders in our study. This discrepancy may have been attributable to the fact that pneumoperitoneum can induce significant increases in systemic vascular resistance (SVR) [38]. The trending ability of pressure waveform devices to accurately monitor changes in SVI is influenced by SVR $[39,40]$. Renner et al. reported that increasing IAP to $25 \mathrm{mmHg}$ abolishes the ability of SVV to predict fluid responsiveness, but not in the case of PPV [12]. This supports our finding that PPV was better able to predict fluid responsiveness than SVV with all of the tested $V_{T}$ values at 6 and $8 \mathrm{ml} / \mathrm{kg}$.

Our study showed discordant results versus those of previous studies regarding the reliability of dynamic preload indices in predicting fluid responsiveness, as well as the appropriate cut-off value [11-15]. These conflicting results can be explained by the fact that the cardiopulmonary interactions that are altered during pneumoperitoneum depend on the level of IAP [41]. Although IAP elevations $>20 \mathrm{mmHg}$ are known to progressively increase the values of dynamic preload indices independent of volume status [12, 13], the lower IAP $(10-15 \mathrm{mmHg})$ in a surgical setting did not modify the cut-off values of dynamic preload indices in the present or previous studies [11, 14, 15]. 
Unlike the results of Hoiseth et al. [14], which showed relatively poor predictive capability of dynamic preload indices for fluid responsiveness during laparoscopy, we found good predictive capability of PPV at $\mathrm{V}_{\mathrm{T}} 8 \mathrm{ml} / \mathrm{kg}$. This discrepancy can be explained by those researchers not controlling clinical factors, such as blood loss, use of vasopressors, or changes in ventilator settings, which may have altered PPV values independent of the preload condition, whereas we performed VE under controlled clinical conditions with little or no surgical stimulation.

Due to the complex relationship between intrathoracic pressure and IAP, as well as the effect of pressure transmitted to pleura space $[42,43]$, during pneumoperitoneum, the detection of hypovolemia is particularly difficult. In addition, protective ventilation strategies [18], specifically small $V_{T}$, have been shown to modify the reliability of dynamic preload indices [44]. However, this study showed that the absolute change in PPV after a " $\mathrm{V}_{\mathrm{T}}$ challenge" reliably predicted fluid responsiveness even under the above limited conditions. As suggested by Myatra et al. [19], the $V_{T}$ challenge can be applied in resource-limited settings as this test does not require a continuous cardiac output monitor. Because $\triangle P P V_{V E}$ were significantly correlated with percentage changes in SVI induced by VE (Fig. 3), fluid responsiveness after VE also can be confirmed without continuous cardiac output monitoring.

Nevertheless, $24 \%$ of patients were included in the grey zone analysis of $\triangle \mathrm{PPV}_{6-8}$, suggesting caution in using of the single cutoff $\left(\triangle \mathrm{PPV}_{6-8}>1 \%\right)$ as the sole target in hemodynamic management. Furthermore, hemodynamic resuscitation should be aimed at achieving not only adequate SV but also sufficient MAP for the body to maintain tissue oxygenation [45]. Because the arterial pressure response VE depends on arterial tone, knowing whether a patient is preload-dependent provides only a partial solution to the problem [46]. In this regard, functional assessment of arterial load by dynamic arterial elastance (Eadyn), defined as the ratio between PPV and SVV has recently been shown to predict the arterial pressure response to VE in hypotensive, preload-dependent patients [47]. Further studies are needed to determine whether this parameter is effective in pneumoperitoneum, using timesynced data from patient monitor and cardiac output monitor [48].

This study had several limitations. First, the study population consisted of only a small number of highly selected patients receiving robot-assisted laparoscopic surgery in the Trendelenburg position. As the IAP was maintained at $15 \mathrm{mmHg}$, our results cannot be extrapolated to different IAP values. Our results require validation in a larger and more heterogeneous population. Second, we performed the $V_{T}$ challenge for $3 \mathrm{~min}$, not $1 \mathrm{~min}$ as described previously [19]. We used an extended time because we have assumed that extending the time for $\mathrm{V}_{\mathrm{T}}$ challenge may have sensitized the test and possibly led to more observations of increases in PPV and SVV. However, during extended time, some equilibrium or compensatory effects could be occurred, which may be an important reason to explain the difference in our cut off values from the study of Myatra et al. [19]. Third, there were sex differences between the responders and non-responders, which may have been due to differences in types of surgery based on sex, resulting in different hemodynamic status at the start of the study protocol. However, we considered it unlikely that this difference would have affected our primary outcome in predicting the fluid response during robotassisted laparoscopic surgery in the Trendelenburg position because the IAP and angle of Trendelenburg position during surgery were constant in all patients.

\section{Conclusions}

In conclusion, the change in PPV following the $\mathrm{V}_{\mathrm{T}}$ challenge test has excellent reliability in predicting fluid responsiveness in patients undergoing robot-assisted laparoscopic surgery in the Trendelenburg position under lung-protective ventilation. The change in SVV and absolute values of PPV and SVV following this test are also reliable.

\section{Abbreviations \\ AUC: Area under the curve; BMI: Body mass index; Cl: Confidence interval; Crs: Compliance of the respiratory system; ECG: Electrocardiography; HR: Heart rate; IAP: Intra-abdominal pressure; MAP: Mean arterial pressure; ODM: Oesophageal Doppler monitor; PBW: Predicted body weight; PEEP: Positive end expiratory pressure; PIP: Peak inspiratory airway pressure Pulse pressure variation; PP: Pulse pressure; PV: Peak velocity; RBF: Renal blood flow; SVI: Stroke volume index; SW: Stroke volume variation; VE: Volume expansion; $V_{\mathrm{T}}$ : Tidal volume}

\section{Authors' contributions}

J-HJ: concept/design, data collection, drafting article, approval of article. RKC: concept/design, critical revision of article, approval of article. HJB: data collection, critical revision of article, approval of article. MHC: data collection, critical revision of article, approval of article. J-SH: data collection, critical revision of article, approval of article. Y-GL: data analysis/interpretation, critical revision of article, approval of article. S-HP: data analysis/interpretation, critical revision of article, approval of article. All authors read and approved the final manuscript.

\section{Funding}

This research was supported by the Hallym University Research Fund, 40074 (HURF-2017-51). The funding body had no influence on study design, data collection and analysis, decision to publish, or preparation of the manuscript.

\section{Availability of data and materials}

The datasets generated and/or analysed during the current study are not publicly available due to the regulation of Institutional Review Board, but are available from the corresponding author after getting permission from IRB for sharing the dataset on reasonable request.

Ethics approval and consent to participate

This study was performed according to the Declaration of Helsinki after the approval of Institutional Review Board of Hallym University Kangnam Sacred Heart Hospital (2017-09-003). Written informed consent was obtained from the enrolled patients before surgery. 


\section{Consent for publication}

Not applicable.

\section{Competing interests}

The authors declare that they have no competing interests.

\section{Author details}

'Department of Anesthesiology and Pain Medicine, Kangnam Sacred Heart Hospital, Hallym University, College of Medicine, Seoul, South Korea. 2Department of Anesthesiology and Pain Medicine, Ewha Womans University, College of Medicine, Anyangcheon-ro, Yangcheon-gu, Seoul 1071, South Korea. ${ }^{3}$ Department of Urology, Kangnam Sacred Heart Hospital, Hallym University, College of Medicine, Seoul, South Korea. ${ }^{4}$ Department of Obstetrics and Gynecology, Kangnam Sacred Heart Hospital, Hallym University, College of Medicine, Seoul, South Korea.

Received: 6 June 2019 Accepted: 18 July 2019

Published online: 07 August 2019

\section{References}

1. Novara G, Ficarra V, Rosen RC, Artibani W, Costello A, Eastham JA, Graefen M, Guazzoni G, Shariat SF, Stolzenburg JU, et al. Systematic review and meta-analysis of perioperative outcomes and complications after robot-assisted radical prostatectomy. Eur Urol. 2012;62(3):431-52

2. Khoury W, Jakowlev K, Fein A, Orenstein H, Nakache R, Weinbroum AA. Renal apoptosis following carbon dioxide pneumoperitoneum in a rat model. J Urol. 2008;180(4):1554-8,

3. Wiesenthal JD, Fazio LM, Perks AE, Blew BD, Mazer D, Hare G, Honey RJ, Pace KT. Effect of pneumoperitoneum on renal tissue oxygenation and blood flow in a rat model. Urology. 2011;77(6):1508 e1509-15.

4. Bergman S, Nutting A, Feldman LS, Vassiliou MC, Andrew CG, Demyttenaere S, Woo D, Carli F, Jutras L, Buthieu J, et al. Elucidating the relationship between cardiac preload and renal perfusion under pneumoperitoneum. Surg Endosc. 2006;20(5):794-800.

5. Demyttenaere SV, Tagi A, Polyhronopoulos GN, Bergman S, Stanbridge DD, Unikowsky B, Carli F, Fried GM, Feldman LS. Targeting individual hemodynamics to maintain renal perfusion during pneumoperitoneum in a porcine model. Surgery. 2007;142(3):350-6.

6. Sharma KC, Brandstetter RD, Brensilver JM, Jung LD. Cardiopulmonary physiology and pathophysiology as a consequence of laparoscopic surgery. Chest. 1996;110(3):810-5.

7. Lestar M, Gunnarsson L, Lagerstrand L, Wiklund P, Odeberg-Wernerman S. Hemodynamic perturbations during robot-assisted laparoscopic radical prostatectomy in 45 degrees Trendelenburg position. Anesth Analg. 2011; 113(5):1069-75.

8. Marik PE, Cavallazzi R, Vasu T, Hirani A. Dynamic changes in arterial waveform derived variables and fluid responsiveness in mechanically ventilated patients: a systematic review of the literature. Crit Care Med. 2009;37(9):2642-7.

9. Hong JQ, He HF, Chen ZY, Du ZS, Liu WF, Weng PQ, Huang HB. Comparison of stroke volume variation with pulse pressure variation as a diagnostic indicator of fluid responsiveness in mechanically ventilated critically ill patients. Saudi Med J. 2014;35(3):261-8.

10. Yang $X, D u B$. Does pulse pressure variation predict fluid responsiveness in critically ill patients? A systematic review and meta-analysis. Crit Care. 2014; 18(6):650.

11. Bliacheriene F, Machado SB, Fonseca EB, Otsuke D, Auler JO Jr, Michard F. Pulse pressure variation as a tool to detect hypovolaemia during pneumoperitoneum. Acta Anaesthesiol Scand. 2007:51(9):1268-72.

12. Renner J, Gruenewald M, Quaden R, Hanss R, Meybohm P, Steinfath M, Scholz J, Bein B. Influence of increased intra-abdominal pressure on fluid responsiveness predicted by pulse pressure variation and stroke volume variation in a porcine model. Crit Care Med. 2009;37(2):650-8.

13. Jacques D, Bendjelid K, Duperret S, Colling J, Piriou V, Viale JP. Pulse pressure variation and stroke volume variation during increased intra-abdominal pressure: an experimental study. Crit Care. 2011;15(1):R33.

14. Hoiseth LO, Hoff IE, Myre K, Landsverk SA, Kirkeboen KA. Dynamic variables of fluid responsiveness during pneumoperitoneum and laparoscopic surgery. Acta Anaesthesiol Scand. 2012;56(6):777-86.

15. Guinot PG, de Broca B, Bernard E, Abou Arab O, Lorne E, Dupont H. Respiratory stroke volume variation assessed by oesophageal Doppler monitoring predicts fluid responsiveness during laparoscopy. $\mathrm{Br} J$ Anaesth. 2014:112(4):660-4.

16. Futier E, Constantin JM, Paugam-Burtz C, Pascal J, Eurin M, Neuschwander A, Marret E, Beaussier M, Gutton C, Lefrant JY, et al. A trial of intraoperative low-tidalvolume ventilation in abdominal surgery. N Engl J Med. 2013;369(5):428-37.

17. Neto AS, Hemmes SN, Barbas CS, Beiderlinden M, FernandezBustamante A, Futier E, Gajic O, El-Tahan MR, Ghamdi AA, Gunay E, et al. Association between driving pressure and development of postoperative pulmonary complications in patients undergoing mechanical ventilation for general anaesthesia: a meta-analysis of individual patient data. Lancet Respir Med. 2016:4(4):272-80.

18. Park SJ, Kim BG, Oh AH, Han SH, Han HS, Ryu JH. Effects of intraoperative protective lung ventilation on postoperative pulmonary complications in patients with laparoscopic surgery: prospective, randomized and controlled trial. Surg Endosc. 2016;30(10):4598-606

19. Myatra SN, Prabu NR, Divatia JV, Monnet X, Kulkarni AP, Teboul JL. The changes in pulse pressure variation or stroke volume variation after a "tidal volume challenge" reliably predict fluid responsiveness during low tidal volume ventilation. Crit Care Med. 2017:45(3):415-21.

20. Messina A, Montagnini C, Cammarota G, De Rosa S, Giuliani F, Muratore L, Della Corte F, Navalesi P, Cecconi M. Tidal volume challenge to predict fluid responsiveness in the operating room: an observational study. Eur J Anaesthesiol. 2019;36(8):583-91.

21. Linares-Perdomo O, East TD, Brower R, Morris AH. Standardizing predicted body weight equations for mechanical ventilation tidal volume settings. Chest. 2015;148(1):73-8.

22. Deflandre E, Bonhomme V, Hans P. Delta down compared with delta pulse pressure as an indicator of volaemia during intracranial surgery. $\mathrm{Br} J$ Anaesth. 2008;100(2):245-50

23. Zhang J, Critchley LA, Huang L. Five algorithms that calculate cardiac output from the arterial waveform: a comparison with Doppler ultrasound. Br J Anaesth. 2015;115(3):392-402.

24. Guinot PG, de Broca B, Abou Arab O, Diouf M, Badoux L, Bernard E, Lorne E, Dupont H. Ability of stroke volume variation measured by oesophageal Doppler monitoring to predict fluid responsiveness during surgery. $\mathrm{Br} J$ Anaesth. 2013;110(1):28-33.

25. Lahner D, Kabon B, Marschalek C, Chiari A, Pestel G, Kaider A, Fleischmann E, Hetz H. Evaluation of stroke volume variation obtained by arterial pulse contour analysis to predict fluid responsiveness intraoperatively. $\mathrm{Br} J$ Anaesth. 2009;103(3):346-51.

26. Gouvea G, Diaz R, Auler L, Toledo R, Martinho JM. Evaluation of the pulse pressure variation index as a predictor of fluid responsiveness during orthotopic liver transplantation. Br J Anaesth. 2009;103(2):238-43.

27. Wilkman E, Kuitunen A, Pettila V, Varpula M. Fluid responsiveness predicted by elevation of PEEP in patients with septic shock. Acta Anaesthesiol Scand. 2014:58(1):27-35.

28. Yang SY, Shim JK, Song Y, Seo SJ, Kwak YL. Validation of pulse pressure variation and corrected flow time as predictors of fluid responsiveness in patients in the prone position. $\mathrm{Br} J$ Anaesth. 2013;110(5):713-20.

29. Cecconi M, Parsons AK, Rhodes A. What is a fluid challenge? Curr Opin Crit Care. 2011;17(3):290-5.

30. Hong DM, Lee JM, Seo JH, Min JJ, Jeon Y, Bahk JH. Pulse pressure variation to predict fluid responsiveness in spontaneously breathing patients: tidal vs. forced inspiratory breathing. Anaesthesia. 2014;69(7):717-22.

31. Shrout PE, Fleiss JL. Intraclass correlations: uses in assessing rater reliability. Psychol Bull. 1979;86(2):420-8.

32. Cannesson M, Le Manach Y, Hofer CK, Goarin JP, Lehot JJ, Vallet B, Tavernier B. Assessing the diagnostic accuracy of pulse pressure variations for the prediction of fluid responsiveness: a "gray zone" approach. Anesthesiology. 2011:115(2):231-41.

33. Chiumello D, Carlesso E, Cadringher P, Caironi P, Valenza F, Polli F, Tallarini F, Cozzi P, Cressoni M, Colombo A, et al. Lung stress and strain during mechanical ventilation for acute respiratory distress syndrome. Am J Respir Crit Care Med. 2008:178(4):346-55.

34. Liu Y, Wei LQ, Li GQ, Yu X, Li GF, Li YM. Pulse pressure variation adjusted by respiratory changes in pleural pressure, rather than by tidal volume, reliably predicts fluid responsiveness in patients with acute respiratory distress syndrome. Crit Care Med. 2016;44(2):342-51.

35. Gattinoni L, Chiumello D, Carlesso E, Valenza F. Bench-to-bedside review: chest wall elastance in acute lung injury/acute respiratory distress syndrome patients. Crit Care. 2004;8(5):350-5. 
36. Henny CP, Hofland J. Laparoscopic surgery: pitfalls due to anesthesia, positioning, and pneumoperitoneum. Surg Endosc. 2005;19(9):1163-71.

37. Cinnella G, Grasso S, Spadaro S, Rauseo M, Mirabella L, Salatto P, De Capraris A, Nappi L, Greco P, Dambrosio M. Effects of recruitment maneuver and positive end-expiratory pressure on respiratory mechanics and transpulmonary pressure during laparoscopic surgery. Anesthesiology. 2013; 118(1):114-22.

38. Joris JL, Noirot DP, Legrand MJ, Jacquet NJ, Lamy ML. Hemodynamic changes during laparoscopic cholecystectomy. Anesth Analg. 1993;76(5): 1067-71.

39. Suehiro K, Tanaka K, Funao T, Matsuura T, Mori T, Nishikawa K. Systemic vascular resistance has an impact on the reliability of the Vigileo-FloTrac system in measuring cardiac output and tracking cardiac output changes. Br J Anaesth. 2013;111(2):170-7.

40. Kubitz JC, Annecke T, Forkl S, Kemming Gl, Kronas N, Goetz AE, Reuter DA Validation of pulse contour derived stroke volume variation during modifications of cardiac afterload. Br J Anaesth. 2007;98(5):591-7.

41. Duperret S, Lhuillier F, Piriou V, Vivier E, Metton O, Branche P, Annat G, Bendjelid K, Viale JP. Increased intra-abdominal pressure affects respiratory variations in arterial pressure in normovolaemic and hypovolaemic mechanically ventilated healthy pigs. Intensive Care Med. 2007;33(1):163-71.

42. Jardin F, Genevray B, Brun-Ney D, Bourdarias JP. Influence of lung and chest wall compliances on transmission of airway pressure to the pleural space in critically ill patients. Chest. 1985;88(5):653-8.

43. Hedenstierna $\mathrm{G}$, Larsson A. Influence of abdominal pressure on respiratory and abdominal organ function. Curr Opin Crit Care. 2012;18(1):80-5.

44. De Backer D, Heenen S, Piagnerelli M, Koch M, Vincent JL. Pulse pressure variations to predict fluid responsiveness: influence of tidal volume. Intensive Care Med. 2005;31(4):517-23.

45. Pinsky MR. Targets for resuscitation from shock. Minerva Anestesiol. 2003; 69(4):237-44.

46. Correa TD, Vuda M, Takala J, Djafarzadeh S, Silva E, Jakob SM. Increasing mean arterial blood pressure in sepsis: effects on fluid balance, vasopressor load and renal function. Crit Care. 2013;17(1):R21.

47. Monge Garcia MI, Gil Cano A, Gracia Romero M. Dynamic arterial elastance to predict arterial pressure response to volume loading in preloaddependent patients. Crit Care. 2011;15(1):R15.

48. Lee HC, Jung CW. Vital recorder-a free research tool for automatic recording of high-resolution time-synchronised physiological data from multiple anaesthesia devices. Sci Rep. 2018;8(1):1527.

\section{Publisher's Note}

Springer Nature remains neutral with regard to jurisdictional claims in published maps and institutional affiliations.

Ready to submit your research? Choose BMC and benefit from:

- fast, convenient online submission

- thorough peer review by experienced researchers in your field

- rapid publication on acceptance

- support for research data, including large and complex data types

- gold Open Access which fosters wider collaboration and increased citations

- maximum visibility for your research: over $100 \mathrm{M}$ website views per year

At BMC, research is always in progress.

Learn more biomedcentral.com/submissions 